\title{
Enhancement of a steam-jet refrigerator using a novel application of the petal nozzle
}

\author{
Yuan-Jen Chang ${ }^{\text {a }}$, Yau-Ming Chen ${ }^{\text {b,* }}$ \\ a Opto-Electronics \& System Laboratories, Industrial Technology Research Institute, Taiwan \\ ${ }^{\mathrm{b}}$ Department of Mechanical Engineering, National Taiwan University, Taipei, Taiwan, 106 ROC \\ Received 28 November 1998; received in revised form 15 April 2000; accepted 17 July 2000
}

\begin{abstract}
This study applies a petal nozzle to enhance the performance of a steam-jet refrigeration system. The behavior and characteristics of a petal nozzle are also investigated by testing it under various operating conditions, i.e., generator temperature, evaporator temperature and condenser temperature. In addition, the effect of area ratio (AR of constant area section of ejector to nozzle throat) on ejector performance is studied by testing ejectors with various values of AR. For comparison, a conventional conical nozzle with the same Mach number as that of petal nozzle is also used. Experimental results demonstrate that the compression ratio and the entrainment ratio can be enhanced if the petal nozzle in an ejector with a larger AR value is used. Moreover, for the ejector with a petal nozzle, an optimum AR value exists under which a maximum compression ratio can be found. (C) 2000 Elsevier Science Inc. All rights reserved.
\end{abstract}

\section{Introduction}

The thermal-driven steam-jet refrigeration system has several merits over the conventional electric-driven vapor-compression system, including no moving parts such as the compressor and hence less consumption of electric energy, very little wear and a highly reliable system. In addition, the refrigerant is inexpensive and pollution-free. Although having certain limitations, steam-jet systems are regaining importance, particularly for industrial applications such as the chilling of water to moderate temperatures in process industries [1] and for various manufacturing processes in the pharmaceutical and chemical industries [2].

Fig. 1 illustrates a typical jet-refrigeration cycle. A high-pressure primary fluid produced by the boiler enters the supersonic (i.e., convergent-divergent) nozzle and expands at the exit of the nozzle. The low-pressure produced by this expansion causes a suctioning effect of secondary flow from the evaporator. The two streams begin to mix in the mixing section and, at the end of the constant-area section, the mixing is complete. In the

\footnotetext{
${ }^{*}$ Corresponding author. Tel.: +886-2-23634701; fax: +886-223631755.

E-mail address: ymchen@ccms.ntu.edu.tw (Y.-M. Chen).
}

diffuser section, the mixed stream undergoes a recompression process and decelerates from supersonic to subsonic, ultimately reaching the back pressure at the diffuser outlet. From the condenser, a portion of the liquid refrigerant returns to the evaporator via an expansion valve, while the remainder is transferred back to the generator via a pump.

Numerous theoretical and experimental studies address the design and application of ejectors. Keenan et al. [3] theoretically and experimentally analyzed the ejector for the first time using the one-dimensional continuity, momentum and energy equations. Their investigation is the foundation of ejector analysis and used until now. However, their analysis cannot predict the phenomenon that produces the well-known constant-capacity characteristics. Munday and Bagster [4] proposed a theory to account for this effect. Their theory assumed the existence of an effective (choke) area for the secondary flow to account for this phenomenon. According to their results, this area remains constant and independent of the operating conditions. Huang et al. [5] used their own experimental data and computed this effective area as mentioned by Munday and Bagster. Their results indicated that the effective area does not remain constant, but varies with the operating conditions. Chen [6] theoretically optimized an ejector refrigerator driven by waste heat in a cooling cycle of an automobile engine. 


\begin{tabular}{|c|c|c|c|}
\hline & & Nomenclature & entrainment ratio \\
\hline & & AR the area ratio of constant area section of ejector & \\
\hline & & to nozzle throat $\left(d_{\mathrm{t}_{2}} / d_{\mathrm{t}_{1}}\right)^{2}$ & Subscripts \\
\hline & & diameter, $\mathrm{mm}$ & b back condition of ejector \\
\hline & & exit Mach number at primary nozzle & generator \\
\hline & & mass flow rate, $\mathrm{kg} / \mathrm{s}$ & primary flow \\
\hline & & pressure, bar or Torr & secondary flow \\
\hline & & heat transfer rate, $\mathrm{kW}$ & primary nozzle throat \\
\hline & & temperature, ${ }^{\circ} \mathrm{C}$ & ejector throat \\
\hline & & $W_{\text {mec }}$ mechanical power, $\mathrm{kW}$ & exit of primary nozzle \\
\hline & & Greeks & Superscript \\
\hline & & $\Delta h \quad$ enthalpy difference, $\mathrm{kJ} / \mathrm{kg}$ & * critical condition \\
\hline
\end{tabular}

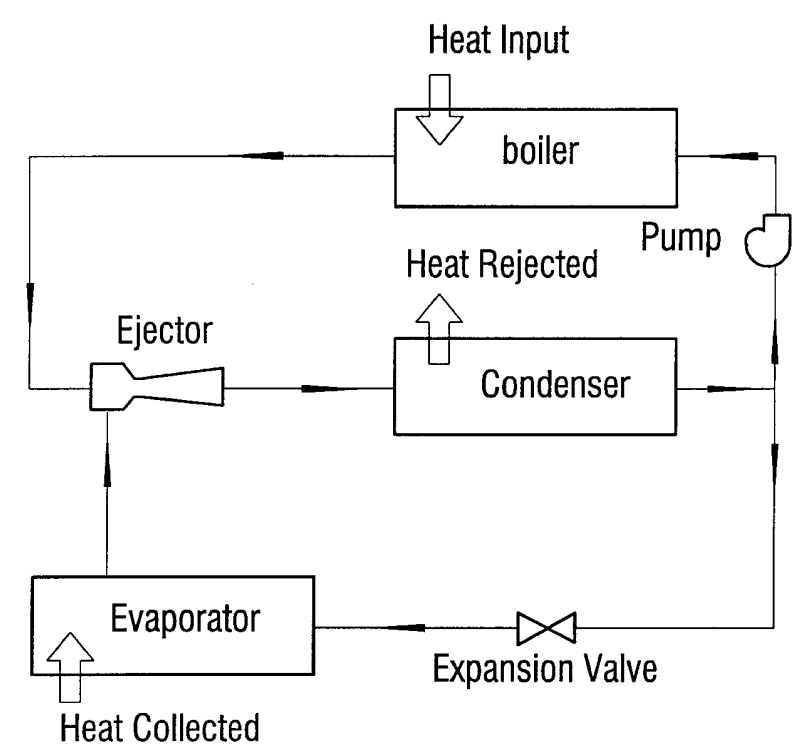

Fig. 1. Schematic diagram of jet-refrigeration cycle.

The optimum performance of the ejector at design point can be determined in his study. Eames et al. [7] recognized the potential of steam-jet refrigerator to utilize low-grade waste heat as its power source. Their subsequent investigation [8] provided a theoretical prediction to estimate the overall COP of this type of refrigeration system. Their experimental data were found to be within $85 \%$ of the theoretical values. The same investigation also thoroughly described the effect of the nozzle position on ejector performance [9]. Later, Chen and Sun [10] proposed a two-stage ejector configuration to enhance the entrainment ratio in the second stage ejector and in doing so, to utilize the lowgrade heat to reduce the operational cost of a refrigeration system. While considering some practical applications of steam-jet vacuum cooling systems, Decker [2] described their use for various manufacturing processes in the pharmaceutical and chemical industries. In those applications, the steam-jet refrigeration systems can be more competitive than the mechanical compressor systems.
The optimum design of a fixed-geometry ejector depends on its application. In refrigeration applications, for example, the evaporator pressure is constrained to the cooling room temperature and the primary pressure is limited by the availability of a fixed boiler temperature. On the other hand, the entrainment ratio is limited by the ejector critical back pressure. If the ejector back pressure exceeds the critical back pressure of the ejector, the entrainment ratio markedly decreases and the ejector finally loses its function. Giving such a constraint, the COP of refrigeration system can be enhanced only by increasing the entrainment ratio but not decreasing the critical back pressure simultaneously.

As well known in the study and application of a steam-jet refrigeration system, the standard ejector is still the most widely used despite the fact that there are various designs of an ejector, such as multi-tube ejector and parietal ejector. To promote the critical back pressure and entrainment ratio of an ejector, this study applies a novel type of petal nozzle. This kind of nozzle was originally developed in aerodynamic field for augmenting thrust force. Using the petal nozzle allows us to reduce the engine's jet noise and to increase the thrust force in the high-speed jet engine [11-14]. According to their results, a well known streamwise vortex existing behind the exit of petal nozzle was found. The normal vortex (due to the Kelvin-Helmholtz instability) sheds periodically from the trailing edge of petal nozzle and plays a large role in the enhanced mixing process in combination with the streamwise vorticity. Therefore, if more efficient mixing in ejector can be achieved by using petal nozzle, then more energy saved can be recovered to the back pressure. Until now, however, petal nozzle has not been applied to ejector refrigeration. Moreover, information regarding the mixing ability of petal nozzle using steam as its working fluid is lacking. Therefore, this study applies and tests a typical six-lobe petal nozzle, which is the most commonly used one in aerodynamic research. In addition, the characteristics of ejector with petal nozzle are also examined for various area ratios (AR value). Moreover, our results are compared with those of the conventional conical nozzle. 


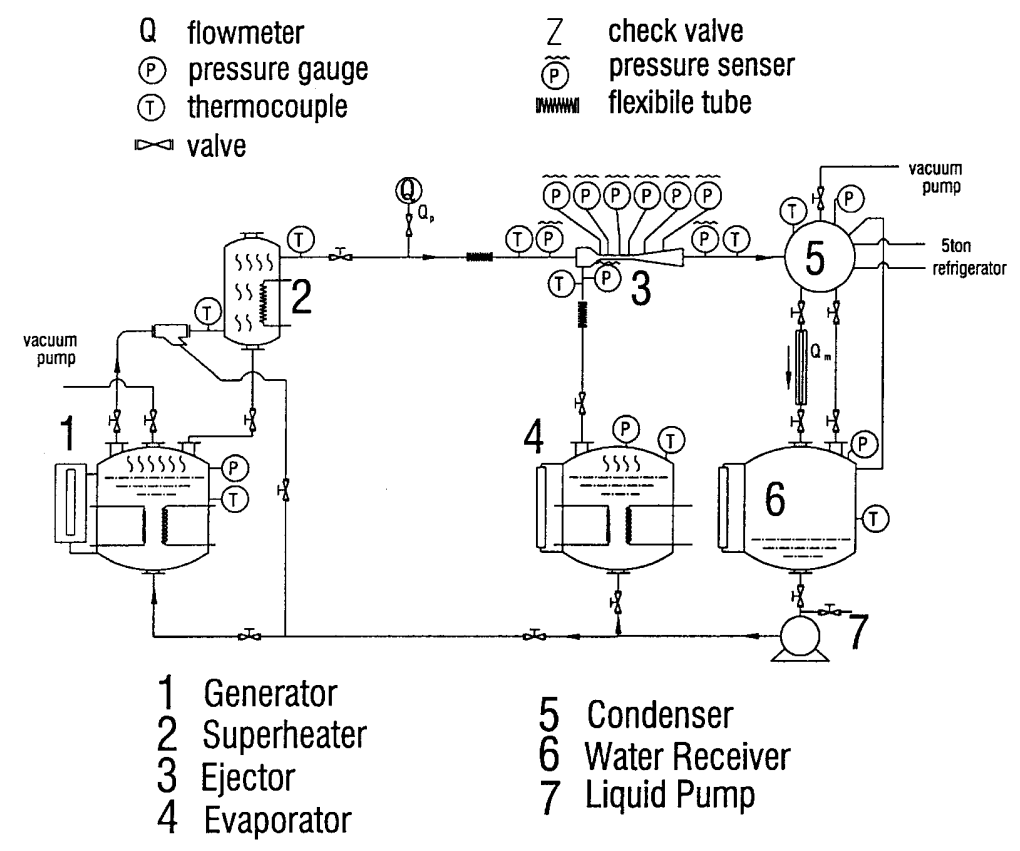

Fig. 2. Schematic description of experimental setup.

\section{Experiments}

\subsection{Apparatus}

Fig. 2 schematically depicts the experimental setup. The apparatus largely consists of a boiler (1), superheater (2), ejector (3), evaporator (4), condenser (5), water receiver (6), liquid pump (7), and measurement devices. The steam generator is equipped with a $12 \mathrm{~kW}$ heating element and a safety value. An SCR controller is used to control the temperature within $\pm 0.1{ }^{\circ} \mathrm{C}$. Next, a vapor-liquid separator is installed between the boiler and superheater. The high-pressure vapor leaving the superheater is then superheated before entering the primary nozzle. The evaporator is equipped with a $6 \mathrm{~kW}$ heater controlled by a SCR controller to control temperature within $\pm 0.1^{\circ} \mathrm{C}$. The exit mixture vapor from the ejector is condensed in a shell-and-tube condenser having a heat transfer area of $2.0 \mathrm{~m}^{2}$. A chiller of $5 \mathrm{t}$ refrigeration capacity provides the cooling water used in the condenser. A PID controller is used to control the condensing temperatures to within $\pm 0.2^{\circ} \mathrm{C}$ and thus, adjust the back pressures of the ejector.

The T-type thermocouples are installed in the desired locations (T1-T9) to measure the temperatures. Calibration of the thermocouples indicates that the accuracy is within $\pm 0.1^{\circ} \mathrm{C}$. The variable-capacitance type pressure transducers (P6, P7) are installed at the inlet of the secondary flow and the exit of the ejector to measure their absolute vacuum pressures. The accuracy of such a sensor is $\pm 0.25 \%$ of the full scale (100 Torr). The inlet pressure of the ejector is measured by a strain-gauge pressure transducer (P5) whose accuracy is $\pm 0.1 \%$ of the full scale $\left(10 \mathrm{kgf} / \mathrm{cm}^{2}\right)$. The solid-state pressure sensors are used to measure the wall pressures with an accuracy of around \pm 1.0 Torr. The flow rate of the primary flow is measured by a differential-pressure type flowmeter. The accuracy of this flowmeter is $\pm 1.0 \%$ of the reading value. While, considering the low absolute pressure of the secondary vapor flow, we do not directly measure its flow rate. Instead, a marked glass tube $25.4 \mathrm{~mm}$ I.D. and $300 \mathrm{~mm}$ long is installed under the condenser to accumulate the mixture water flow leaving the condenser. The time interval during the liquid level reaching the bottom and top marks of the glass tube is measured by a digital timer. The combined flow rate can be calculated simply by dividing the time period into the known volume between the two marks. Correspondingly, the secondary mass flow rate is obtained by subtracting the primary mass flow rate from the mixture mass flow rate.

\subsection{Ejector configurations}

The ejector is the most important compartment of the system. Fig. 3 illustrates the configuration of the

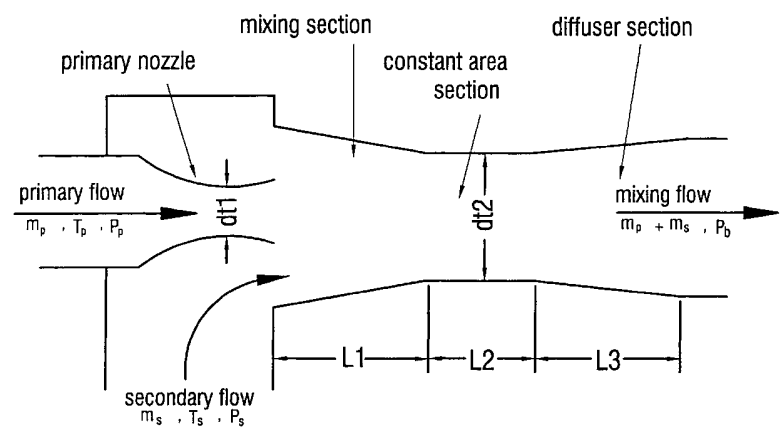

Fig. 3. Configuration and dimensions of ejector. 
Table 1

The detailed geometry of an ejector

\begin{tabular}{llllll}
\hline & $d_{\mathrm{t}_{1}}(\mathrm{~mm})$ & $\left(d_{\mathrm{t}_{2}} / d_{\mathrm{t}_{1}}\right)^{2}$ & $\left(L_{1} / d_{\mathrm{t}_{2}}\right)$ & $\left(L_{1} / d_{\mathrm{t}_{2}}\right)$ & $\left(L_{1} / d_{\mathrm{t}_{2}}\right)$ \\
\hline EJ1 & 2 & 80 & 6 & 4 & 6 \\
EJ2 & 2 & 100 & 6 & 4 & 6 \\
EJ3 & 2 & 196 & 6 & 4 & 6 \\
EJ4 & 2 & 300 & 6 & 4 & 6 \\
\hline
\end{tabular}

ejectors. Table 1 lists the corresponding geometric dimensions. Herein, four ejectors with various area ratios (AR value), i.e., $\left(d_{\mathrm{t}_{2}} / d_{\mathrm{t}_{1}}\right)^{2}$, are tested. The corresponding AR is $80,100,196$ and 300 . The ratio of mixing section length $\left(L_{1}\right)$, constant area section length $\left(L_{2}\right)$ and diffuser section length $\left(L_{3}\right)$ to diameter of constant area section $\left(d_{\mathrm{t}_{2}}\right)$ is fixed, i.e., $\left(L_{1} / d_{\mathrm{t}_{2}}\right):\left(L_{2} / d_{\mathrm{t}_{2}}\right):\left(L_{3} / d_{\mathrm{t}_{2}}\right)=6: 4: 6$. The design rule is provided from Ref. [1].

\subsection{Petal nozzle configurations}

Fig. 4(a) provides the detailed dimensions of a petal nozzle. Fig. 4(b) displays the conical nozzle which is intended for use as a comparison with the petal nozzle. The throat area and exit area of both nozzles are 3.14 and $63.4 \mathrm{~mm}^{2}$, respectively. The exit Mach number of both nozzles is 4.35 , which is evaluated by assuming an isentropic and one-dimensional flows. Notably, the shape of exit plane of petal nozzle is six-lobes. In addition, the designed rule is provided from the reference [13-15]. Moreover, the nozzle inside is well machined to avert friction loss.

\subsection{Experimental procedure}

The experimental system is first evacuated by a vacuum pump until its pressure equals the saturation pressure corresponding to the water temperatures at the generator and evaporator. The tap water in the generator is then heated to generate the motive high-pressure vapor. Before turning on the SCR-controlled heater of the evaporator, the tap water in the evaporator is initially cooled to the required temperature by a chiller of $2 \mathrm{t}$ refrigeration capacity. The high-pressure vapor

(a) conical nozzle

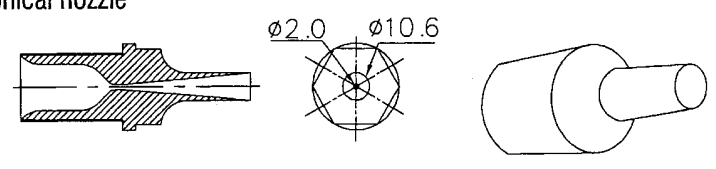

(b) petal nozzle
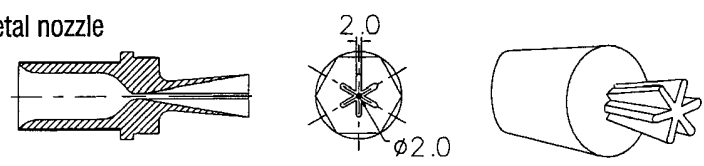

Fig. 4. Primary nozzle geometries under investigation. (primary flow) enters the primary nozzle of the ejector and induces the low-pressure vapor (secondary flow) from the evaporator. The formed mixture vapor is condensed in the condenser and flows down into the water receiver by gravity. As the steady-state condition is reached, the corresponding flow rate, temperatures and pressures are recorded. At this moment, the valves V7 and V9 are closed and the valve V6 is opened to measure the mixture flow rate several times, as mentioned earlier.

The batch-type experimental system used herein is designed to run for at least $2 \mathrm{~h}$. After one experiment has been conducted, the valves V12-V14 are opened and the others are closed. The water in the receiver is then pumped back to the generator and evaporator to restart another experiment.

\subsection{Experimental uncertainty}

Uncertainties in three diameters of the ejectors, $d_{\mathrm{t}_{1}}$, $d_{\mathrm{t}_{2}}$, and $d_{\mathrm{x}}$, are less than $\pm 5.0 \%$. A detailed error analysis based on the inaccuracies involved in measuring the temperature, volume between two marks of the glass tube, and time interval reveals that the maximum uncertainty in the calculated value of the mixture mass flow rate is $\pm 1.7 \%$. From the error incurred in measuring the mixture mass flow rate and the primary mass flow rate, the uncertainties in the secondary mass flow rate and the entrainment ratio are determined to be $\pm 3.4 \%$ and $\pm 3.8 \%$, respectively.

In this experiment, four ejectors with wide range of AR values $(80,100,196,300)$ with petal and conical nozzles are tested at various operating conditions: generator temperature, evaporator temperature and condenser temperature. The given Mach number of the petal nozzle and conical nozzle is the same 4.35. Table 2 summarizes the range of parameters covered during experimentation.

Table 2

The parameter tested in this study

\begin{tabular}{rrll}
\hline$M a$ & $\mathrm{AR}$ & $P_{\mathrm{p}}(\mathrm{atm}) / T_{\mathrm{p}}\left({ }^{\circ} \mathrm{C}\right)$ & $P_{\mathrm{s}}(\mathrm{Torr}) / T_{\mathrm{s}}\left({ }^{\circ} \mathrm{C}\right)$ \\
\hline 4.35 & 80 & $1.16 / 105$ & $9.85 / 11$ \\
& 100 & $1.53 / 110$ & $14.50 / 17$ \\
& 196 & $1.98 / 120$ & $17.54 / 20$ \\
& 300 & $2.70 / 130$ & \\
\hline
\end{tabular}




\section{Results and discussion}

Before discussing the results, the relation between coefficient of performance (COP) and entrainment ratio is presented herein. The COP of a refrigeration cycle is defined as the ratio between the generated refrigeration and the energy input into the cycle. Let $Q_{\mathrm{e}}$ and $Q_{\mathrm{g}}$ be the heat exchange rates in the evaporator and generator, respectively. Let $W_{\text {mec }}$ be the mechanical power required by the cycle (by the pump). The COP of the ejector refrigeration cycle is then defined as

$$
\begin{aligned}
\mathrm{COP} & =Q_{\mathrm{e}} /\left(Q_{\mathrm{g}}+W_{\text {mec }}\right) \\
& =m_{\mathrm{s}} \times \Delta h_{\mathrm{e}} /\left(m_{\mathrm{p}} \times \Delta h_{\mathrm{g}}+W_{\text {mec }}\right) .
\end{aligned}
$$

Herein, $\Delta h_{\mathrm{e}}$ and $\Delta h_{\mathrm{g}}$ are enthalpy differences in the evaporator and generator, respectively, and $m_{\mathrm{s}}$ and $m_{\mathrm{p}}$ are the mass flow rates of the secondary vapor and primary vapor, respectively. In the ejector refrigeration cycle, $W_{\text {mec }}$ can be neglected as compared to the energy required in the generator. The entrainment ratio $\omega$ of the ejector is defined as

$\omega=m_{\mathrm{s}} / m_{\mathrm{p}}$.

Correspondingly, the COP of the cycle can be rearranged as

$\mathrm{COP}=\omega \times\left(\Delta h_{\mathrm{e}} / \Delta h_{\mathrm{p}}\right)$.

Therefore, the entrainment ratio is proportional to the COP and is an important parameter when evaluating the performance characteristics of ejector refrigeration cycles.

\subsection{Characteristics of the ejector with a petal nozzle}

\subsubsection{Effect of back pressure}

For a situation in which the pressures of primary flow and secondary flow are fixed, Fig. 5 depicts the relations between entrainment ratio and back pressure. The primary flow pressure $P_{\mathrm{p}}$ is $1.53 \mathrm{~atm}$ and the secondary flow pressure $P_{\mathrm{s}}$ is 17.54 Torr (the corresponding saturation temperature $T_{\mathrm{s}}=20.0^{\circ} \mathrm{C}$ ). According to this figure, the secondary vapor flow begins to be entrained by the ejector when the back pressure is decreased to around 26.0 Torr. That is, $P_{\mathrm{b}}<P_{\mathrm{b}}^{0}$, where $P_{\mathrm{b}}^{0}$ denotes the maximum back pressure that the ejector begins to entrain. As the back pressure is further decreased, the secondary mass flow rate increases, thereby increasing the entrainment ratio. However, as back pressure falls below a critical back pressure $P_{\mathrm{b}}^{*}$ (about 20.9 Torr), the entrainment ratio would not increase further, but remains constant. This is the maximum entrainment ratio $\omega$ at this operating condition. This observation reveals that the secondary flow is choked. This choking phenomenon resembles the ejector equipped with conventional conical nozzle $[4,5]$. Both critical back pressures $P_{\mathrm{b}}^{*}$ and $\omega$ are the most important indicators for evaluating the operation performance of steam-ejectors. The higher critical back pressure and entrainment ratios imply a better ejector performance. Fig. 5 plots the data of ejector with

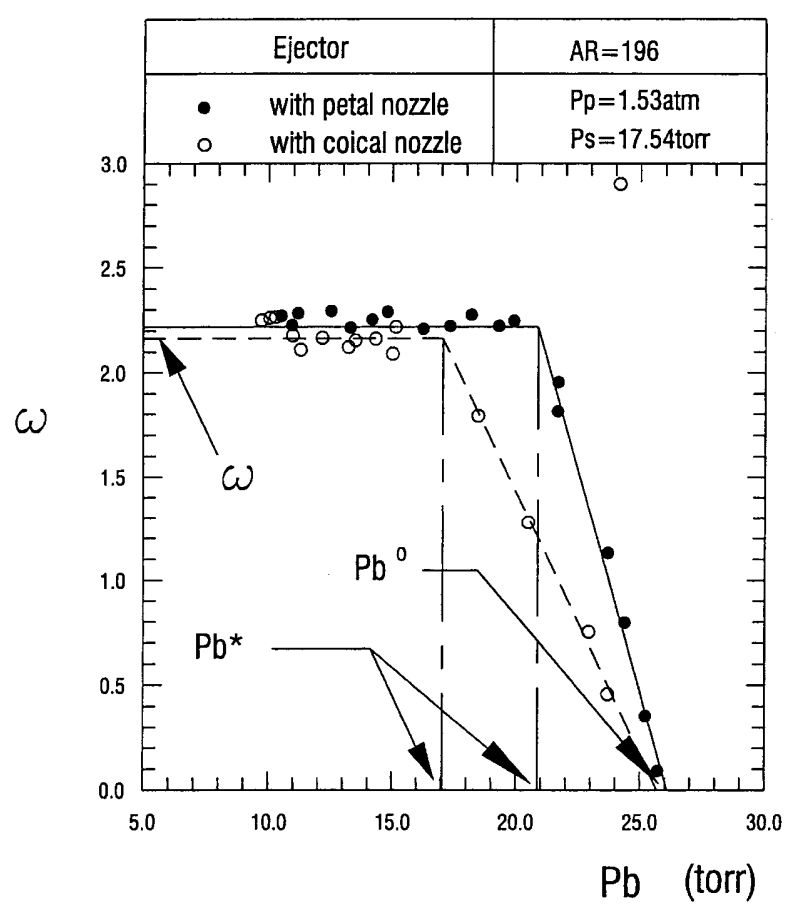

Fig. 5. Effect of back pressure of ejector with conical and petal nozzles.

conical nozzle on the same operating conditions for comparison. Under this operating condition, the entrainment ratio $\omega$ is slightly higher for the ejector with a petal nozzle. However, the critical back pressure $P_{b}^{*}$ is larger for an ejector with a petal nozzle about 4 Torr than that with a conical nozzle. Obviously, the ejector equipped with petal nozzle still has the ability of compression even under the conditions of large entrainment ratio.

\subsubsection{Effect of primary flow pressure}

Fig. 6 plots the entrainment ratio against the back pressure of the ejector for four tested primary flow pressures $P_{\mathrm{p}}$. The exit Mach number $M a$ is 4.35 and the secondary flow pressure $P_{\mathrm{s}}$ remains constant at 9.85 Torr. The variations of $\omega$ with $P_{\mathrm{b}}$ for these four $P_{\mathrm{p}}$ resemble each other, as described in the above section. Let $P_{\mathrm{x}}$ be the discharged pressure of the primary nozzle. For a given supersonic primary nozzle, the pressure ratio $P_{\mathrm{x}} / P_{\mathrm{p}}$ remains nearly constant such that an increasing $P_{\mathrm{p}}$ subsequently increases $P_{\mathrm{x}}$, subsequently decreasing the pressure difference $P_{\mathrm{s}}-P_{\mathrm{x}}$. Obviously, a lower $P_{\mathrm{s}}-P_{\mathrm{x}}$ yields a less entrained flow rate from evaporator. Therefore, the maximum entrainment ratio $\omega$ decreases with an increase of the primary flow pressure. On the other hand, a larger $P_{\mathrm{p}}$ contains more energy and so as the mixtures. Thus, the pressure recovery from kinetic energy in the diffuser also increases. Consequently, the critical back pressure is increased by increasing $P_{\mathrm{p}}$, which would be useful for the condenser to operate at a higher temperature in the refrigeration cycles. A similar trend can be found in the ejectors with a conical nozzle. 


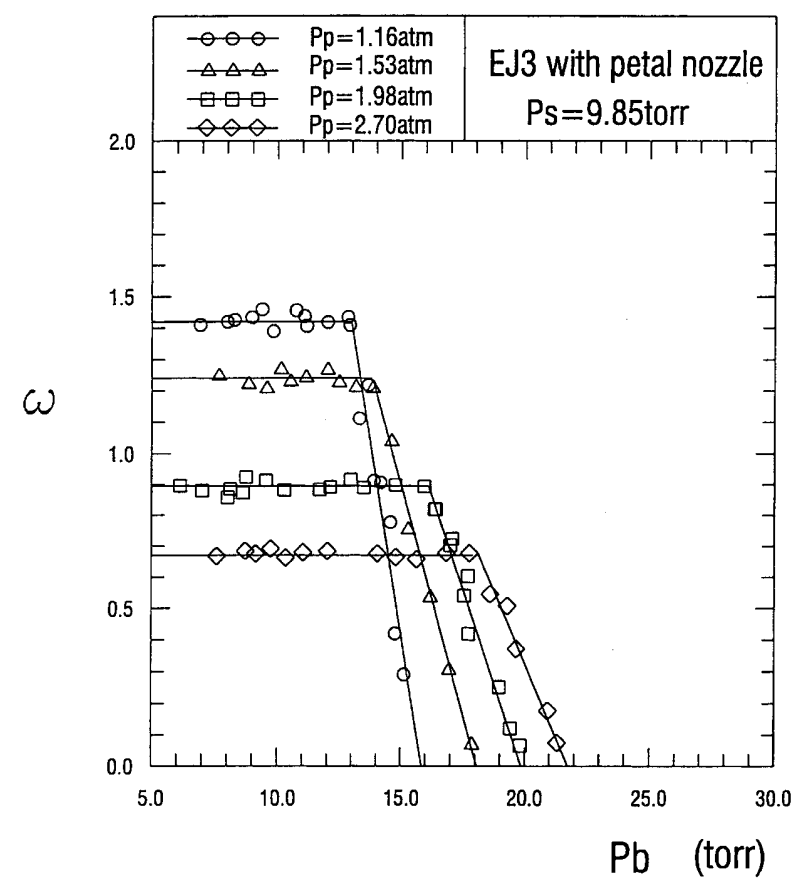

Fig. 6. Effect of primary flow pressure of ejector with petal nozzle.

\subsubsection{Effect of secondary flow pressure}

The pressure of secondary vapor flow $P_{\mathrm{s}}$ is another controlling parameter for the ejector performance. Fig. 7 displays the entrainment ratio as a function of the back pressure at three values of $P_{\mathrm{s}}$ for a given $P_{\mathrm{p}}=1.53 \mathrm{~atm}$. The variations of $\omega$ with $P_{\mathrm{b}}$ for the three tested $P_{\mathrm{s}}$ are qualitatively similar to the curves depicted in Fig. 5.

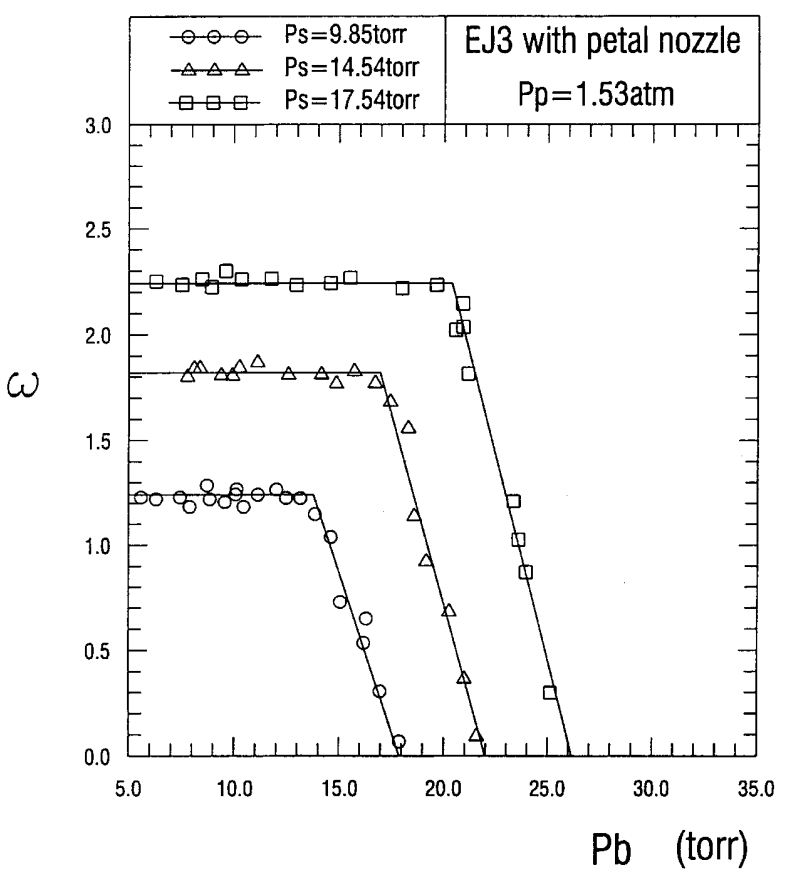

Fig. 7. Effect of secondary pressure of ejector with petal nozzle.
Restated, the ejector entrained rate markedly decreases once $P_{\mathrm{b}}$ exceeds the critical back pressure $P_{\mathrm{b}}^{*}$. Notably, increasing $P_{\mathrm{S}}$ always increases the driving pressure difference $P_{\mathrm{s}}-P_{\mathrm{x}}$ for the given $P_{\mathrm{p}}$ (which has been explained in the previous section), thereby increasing the entrainment ratio.

Furthermore, increasing the secondary flow pressure increases the critical back pressure due to the similar reason described in above section. Although a larger secondary flow pressure has the merits of simultaneously increasing $\omega$ and $P_{\mathrm{b}}^{*}$, the increase of $P_{\mathrm{s}}$ is limited by cooling the room temperature for the practical use of refrigeration systems.

Consequently, the characteristics of ejectors with a petal nozzle are similar as those of conical nozzle. Restated, it is essentially affected by the following parameters: (1) the primary flow pressure $P_{\mathrm{p}}$, (2) the secondary flow pressure $P_{\mathrm{s}},(3)$ the back pressure of the ejector $P_{\mathrm{b}}$, and (4) the mixing length of ejector.

\subsection{Performance characteristics maps of ejector}

Fig. 8 plots the variations of $P_{\mathrm{b}}^{*}$ with the corresponding maximum entrainment ratio $\omega$ under different operating conditions, say $P_{\mathrm{s}}$ and $P_{\mathrm{p}}$, for ejector $\mathrm{AR}=196$. The massy symbol line denotes the petal

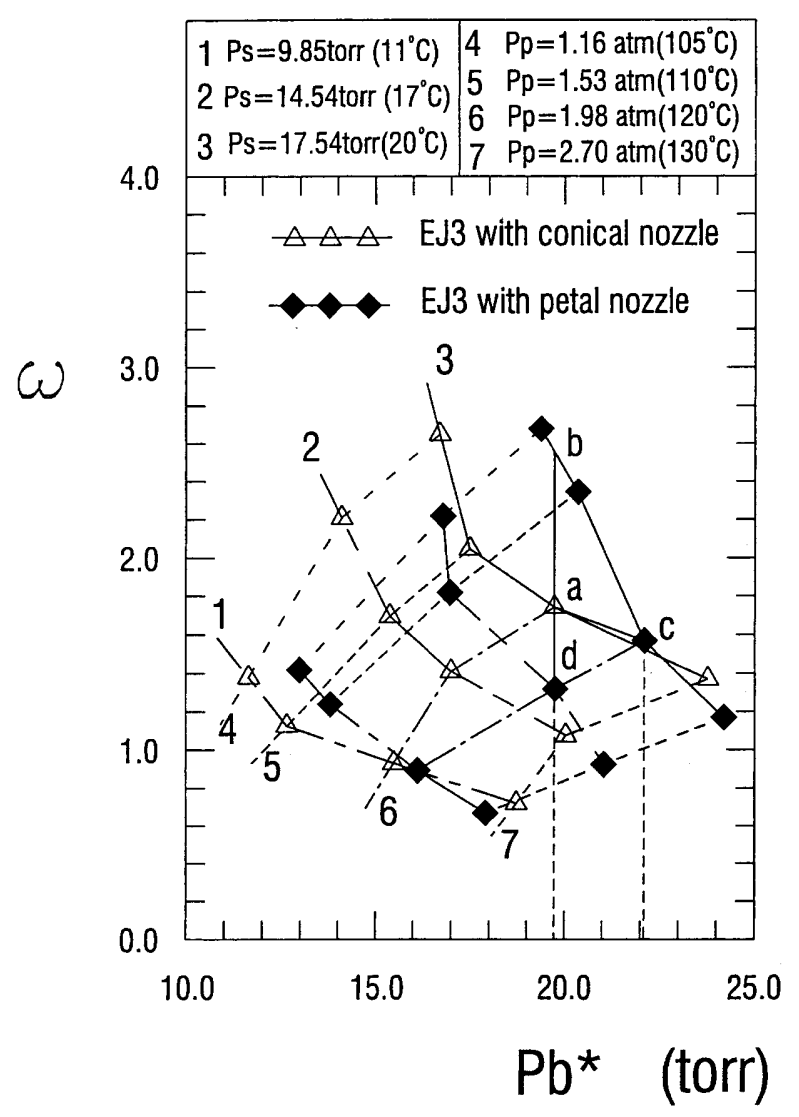

Fig. 8. Variation of entrainment ratio with critical back pressure for different operating conditions. 
nozzle and unsubstantial symbols represent conical nozzle. The various line-types represent the cases that the ejector is running at various given $P_{\mathrm{p}}$ and $P_{\mathrm{s}}$. The constructed maps can be viewed as the operation maps for the ejectors tested herein. According to this figure, the effects of $P_{\mathrm{p}}$ and $P_{\mathrm{s}}$ on $P_{\mathrm{b}}^{*}$ resemble each other. Comparing the two operation maps obtained for different geometrical nozzles, i.e., the petal and conical nozzles, reveals that the back pressure for petal nozzle surpasses that for a conical nozzle under the operating conditions tested. This comparison also reveals that the ejector with a petal nozzle operating at a higher entrainment ratio $(\omega>1)$ more significantly increases in back pressure; however, the increase at a lower entrainment ratio $(\omega<1)$ is not prominent.

\subsection{Practical significance}

If a petal nozzle is used to substitute the conical nozzle under a specified operating condition, e.g., point a in Fig. 8, the performance can be enhanced by the following three methods. Utilization of these three methods depends on the actual circumstances available in the application.

\subsubsection{Constant evaporator temperature, higher COP of steam refrigerator}

Point a to point $b$. If the evaporator temperature and condenser temperature are maintained the same when petal nozzle is used, the cycle operating point moves from $a$ to $b$. This increases the entrainment ratio of steam refrigerator from 1.75 to 2.5 , about $50 \%$ enhancement. Moreover, the boiler temperature can be reduced from $120^{\circ} \mathrm{C}$ to $107^{\circ} \mathrm{C}$. Restated, the capital cost can even be reduced.

\subsubsection{Constant evaporator temperature, higher condenser temperature \\ Point a to point $c$. If the evaporator temperature is maintained the same when a petal nozzle is used, the cycle operating point moves from a to c. This movement produces an increase of critical back pressure about 2.5 Torr. Under other operating conditions, however, the maximum enhancement of 8.8 Torr can be achieved $\left(T_{\mathrm{p}}=130^{\circ} \mathrm{C}, T_{\mathrm{s}}=20^{\circ} \mathrm{C}, \mathrm{AR}=300\right)$. In addition, the boiler temperature is maintained, subsequently causing a decrease of the entrainment ratio from 1.75 to 1.6.}

\subsubsection{Constant boiler temperature, lower evaporator temperature}

Point a to point $d$. If the boiler temperature and condenser temperature are maintained constant when petal nozzle is used, the cycle operating point moves from a to d, subsequently decreasing entrainment ratio from 1.75 to 1.35 . However, the evaporator temperature can be reduced from $20^{\circ} \mathrm{C}$ to $17^{\circ} \mathrm{C}$.

\subsection{Comparison between petal and conical nozzles}

In summing up the experimental results, Fig. 9 plots the performance curves (compression ratio vs entrainment ratio). This figure also plots the data for a conical nozzle for comparison. Notably, the curve which is located on the right upper part of this figure indicates that its performance is better than that located on the left lower part of the figure. This figure also reveals that the performance is higher for an ejector with conical nozzle as $\mathrm{AR}=80$ and 100, i.e., EJ1 and EJ2. In contrast, the performance is higher for an ejector with petal nozzle when the $\mathrm{AR}=196$ and 300, i.e., EJ3 and EJ4. Above results demonstrate that the petal nozzle appears to have the merits of using an ejector with a larger AR value; however, it has the disadvantage of using an ejector with a smaller AR value. This disadvantage may be attributed to that small AR ejector that confines the generation of streamwise vorticity [11] by the petal, subsequently reducing the efficient mixing. On the other hand, if a larger AR ejector is used, the streamwise vorticity can be fully developed, then the efficient mixing can be accomplished. For all the performance curves, however, the entrainment ratio always decreases with an increase of the compression ratio.

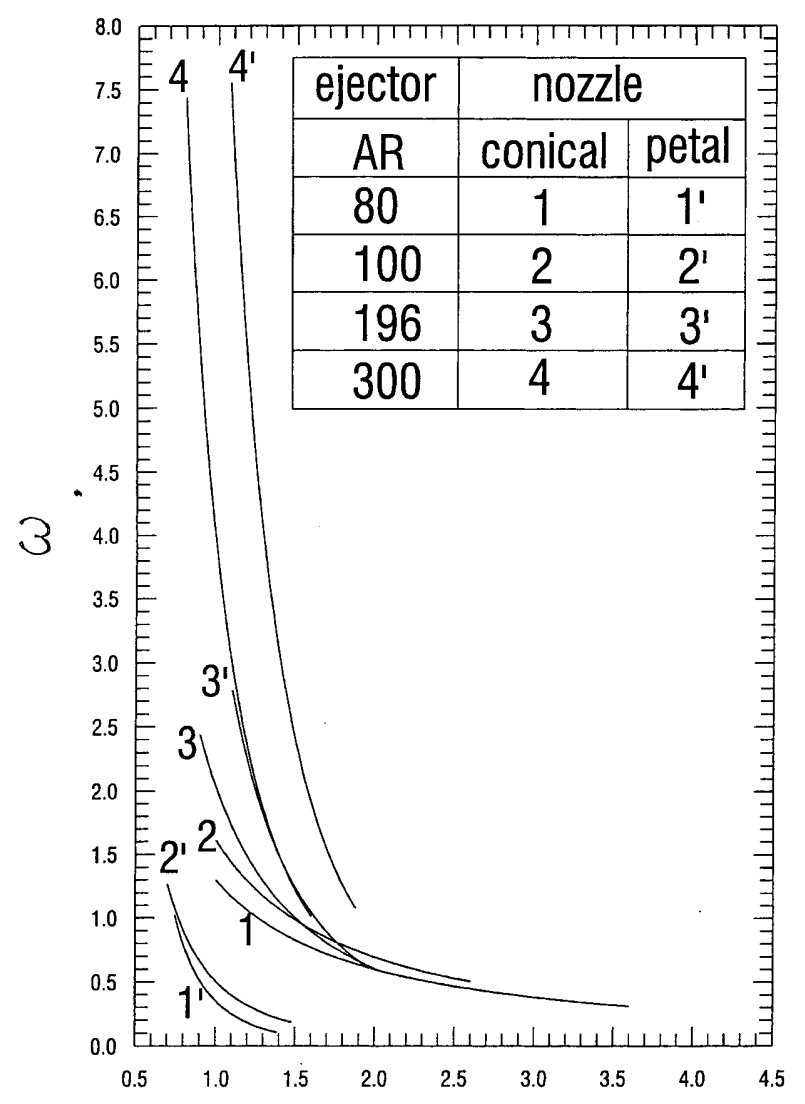

Fig. 9. Comparison of operation performance for different AR values of an ejector with conical and petal nozzles. 


\subsection{Optimum AR value for an ejector with a petal nozzle}

In addition, for a certain compression ratio, the entrainment ratio increases with an increase of AR value, as discussed in the next section. Fig. 10 depicts the variation of compression and entrainment ratio for different AR values. The solid line denotes the variation of compression ratio $\left(P_{\mathrm{b}}^{*} / P_{\mathrm{s}}\right)$ and the dashed line represents the variation of entrainment ratio $(\omega)$. For an ejector with a conical nozzle, its entrainment ratio increases with an increase of the AR value. The occurrence may be attributed to the increase of AR, in which the cross-section of constant area section in ejector becomes larger. The primary flow, however, is still choked by primary nozzle. Consequently, the ejector is more able to swallow more mass flow rate of secondary flow at the same time. However, while entrainment ratio increases, the compression ratio decreases because the energy provided by the primary flow to compress the secondary flow in the same. For an ejector with a petal nozzle, its entrainment ratio also increases with an increase of the AR value. Nevertheless, the variation of compression with AR value is not the same. Initially, the compression ratio increases with an increase of AR from 80 to 196. Next, this ratio reaches a maximum value at about $\mathrm{AR}=220$. As $\mathrm{AR}$ exceeds 220, the compression ratio decreases with an increase of AR. As mentioned earlier, the efficient mixing caused by petal nozzle can reduce mixing energy loss. However, the generation of streamwise vorticity may cause more turbulent flow in the ejector, i.e., this is another extra energy loss. Obviously, for an ejector with $\mathrm{AR}=220$, it attains the balance. Therefore, for this operating condition, the petal

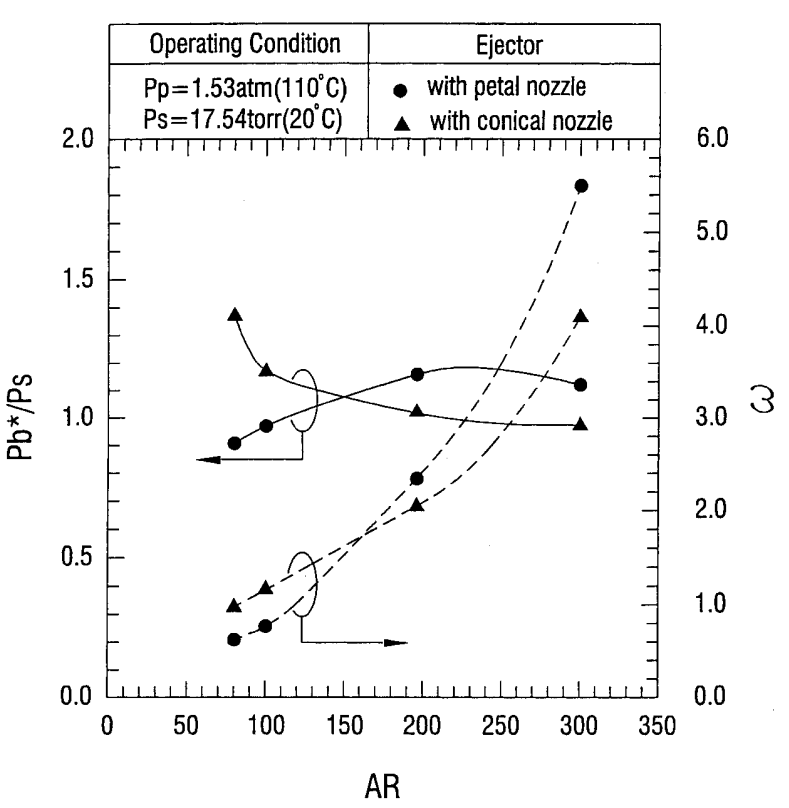

Fig. 10. Variation of compression and entrainment ratio for different AR values. nozzle is appropriate for use in an ejector with $\mathrm{AR}=220$.

Clearly, the performance (compression and entrainment ratio) of ejector with conical nozzle is better than that with petal nozzle as AR is smaller than about 150 . That is, it has the merits of using the petal nozzle in an ejector with a larger AR value. However, it is disadvantageous to use the petal nozzle in an ejector with a smaller AR value.

\section{Conclusions}

This study experimentally investigates a steam-jet refrigerator using petal and conical nozzles. Experimental results indicate that the performance of an ejector with a petal nozzle is better than that with a conical nozzle for a larger AR number. Among all the operating conditions, the ejector with a petal nozzle can operate at a higher critical condenser pressure for a larger AR number. In addition, for the ejector with a petal nozzle, an optimum AR value exists under which a maximum compression ratio can be found. In contrast, such a trend does not occur for the ejector equipped with a conical nozzle.

Adopting the petal nozzle elevates the performance of an ejector. However, owing to its complexity, the flow field inside the ejector is still not fully understood. Therefore, a more detailed design rule for a petal nozzle used in a steam-jet refrigerator must be estabilished. In addition, flow visualization facilitates the identification of an enhanced mechanism for the petal nozzle.

\section{Acknowledgements}

The authors would like to thank the National Science Council of the Republic of China for financially supporting this research under Contract No. NSC 87-2212E-002-082.

\section{References}

[1] ASHRAE, Steam-jet refrigeration equipment, in: 1979 Equipment Handbook, AHRAE, Atlanta, GA, USA 13 (1979).

[2] L.O. Decker, Consider the cold facts about stream-jet vacuum cooling, Chem. Eng. Prog. 89 (1) (1993) 74-77.

[3] J.H. Keenan, E.P. Neumann, F. Lustwerk, An investigation of ejector design by analysis and experiment, ASME J. Appl. Mech. 72 (1950) 299-309.

[4] J.T. Munday, D.F. Bagster, A new ejector theory applied to steam-jet refrigeration, Ind. Eng. Chem., Proc. Res. Dev. 16 (4) (1997) 442-449.

[5] B.J. Huang, C.B. Jiang, F.L. Hu, Ejector performance characteristics and design analysis of jet-refrigeration system, Trans. ASME 107 (1985) 792-802.

[6] L.T. Chen, A heat driven mobile refrigeration cycle analysis, Energy Convers. 18 (1) (1978) 25-29. 
[7] I.W. Eames, S. Aphornratana, Da-Wen Sun, The jet-pump cyclea low cost refrigerator option powered by waste heat, Heat Recovery Syst. CHP 15 (8) (1995) 711-721.

[8] I.W. Eames, S. Aphornratana, H. Haider, A theoretical and experimental study of a small-scale steam-jet refrigerator, Int. J. Refrig. 18 (6) (1995) 378-386.

[9] S. Aphornratana, I.W. Eames, A small capacity steam-ejector refrigerator: experimental investigation of a system using ejector with movable primary nozzle, Int. J. Refrig. 20 (5) (1997) 352358.

[10] Y.M. Chen, C.Y. Sun, Experimental study on heat and mass transfer of a combined absorber-evaporator exchanger, Int. J. Heat Mass 40 (4) (1997) 961-971.
[11] R.W. Parerson, Turbofan mixer nozzle flow field - a benchmark experimental study, ASME J. Eng. Gas Turbines Powers 106 (1984) 692-698.

[12] W.M. Presz, B.L. Morin, R.G. Gousy, Force mixer lobes in ejector designs, J. Propulsion Power 4 (4) (1988) 350-355.

[13] A.K. Narayanan, K.A. Damodaran, Supersonic-ejector characteristics using a petal nozzle, J. Propulsion Power 10 (5) (1994) $742-744$.

[14] A.R. Srikrishnan, J. Kurian, V. Sriramulu, Experimental study on mixing enhancement by petal nozzle in supersonic flow, J. Propulsion Power 12 (1) (1996) 165-169.

[15] S.C.M. Yu, X.G. Xu, Turbulent mixing of coaxial nozzle flows with a central-lobed mixer, J. Propulsion Power 13 (4) (1997) 517-524. 